\title{
Influence of nonsteroidal anti-inflammatory drugs on aspirin's antiplatelet effects and suggestion of the most suitable time for administration of both agents without resulting in interaction
}

\author{
Kenta Shibata ${ }^{1,2^{*}}$ (D, Yuuki Akagi $^{3}$, Naofumi Nozawa ${ }^{1}$, Hitoshi Shimomura ${ }^{1,4}$ and Takao Aoyama ${ }^{1}$
}

\begin{abstract}
Background: Low-dose aspirin irreversibly inhibits platelet cyclooxygenase-1 (COX-1) and suppresses platelet aggregation. It is effective for secondary prevention of cardiovascular events. Because nonsteroidal anti-inflammatory drugs (NSAIDs) reversibly bind with COX-1, the antiplatelet effects of aspirin may be suppressed when NSAIDs are co-administered. This interaction could be avoided by avoiding simultaneous administration; however, the minimum interval that should separate the administration of aspirin and loxoprofen is not well known. In this study, we investigated how to avoid the influence of NSAIDs on the antiplatelet effects of aspirin. An in vitro experiment was performed to investigate the influence of ibuprofen and loxoprofen at various concentrations on aspirin's antiplatelet action.

Methods: Platelet aggregation and thromboxane $B_{2}\left(T X B_{2}\right)$ levels were measured after addition of aspirin only and NSAIDs plus aspirin to platelet-rich plasma. NSAIDs were used at their maximum plasma concentrations, the assumed concentration after $6 \mathrm{~h}$ (for loxoprofen only), and the assumed concentration after $12 \mathrm{~h}$ of taking one clinical dose. Platelet aggregation threshold index (PATI), defined as the putative stimulus concentration giving 50\% aggregation, was calculated as an index of aggregation activity.
\end{abstract}

Results: PATI decreased in ibuprofen plus aspirin group compared to that in the aspirin only group, regardless of ibuprofen concentration. Furthermore, PATI significantly decreased when aspirin was added after loxoprofen-trans-OH addition at the maximum concentration $(4.1 \pm 0.1 \mu \mathrm{g} / \mathrm{mL})$, compared to that in aspirin only group $(5.9 \pm 0.1 \mu \mathrm{g} / \mathrm{mL})$. PATI showed no significant difference after addition of loxoprofen at the assumed concentration after $6 \mathrm{~h}$ (aspirin only group, $5.0 \pm 0.5 \mu \mathrm{g} / \mathrm{mL}$; loxoprofen-trans-OH plus aspirin group, $4.9 \pm 0.4 \mu \mathrm{g} / \mathrm{mL}$ ). In addition, $\mathrm{TXB}_{2}$ concentration tended to decrease with increasing PATI.

Conclusions: It is desirable to avoid ibuprofen co-administration with the usual once-daily low-dose aspirin therapy; however, a 6-h interval between loxoprofen and aspirin could avoid this potential interaction when loxoprofen is taken before aspirin.

Keywords: Aspirin, Antiplatelet, Nonsteroidal anti-inflammatory drugs, Ibuprofen, Loxoprofen, Drug interaction, Human, Cyclooxygenase-1, Coating, Platelet aggregation threshold index

\footnotetext{
* Correspondence: itsumokokokara3039@yahoo.co.jp

The original version of this article was revised: Fig. $5 \mathrm{a}$ and $\mathrm{c}$ was previously

displayed as " $\mu \mathrm{g} / \mathrm{mL}$ " and was corrected to "ng/mL".

"Faculty of Pharmaceutical Sciences, Tokyo University of Science, 2641

Yamazaki, Noda, Chiba 278-8510, Japan

2Department of Pharmacy, Koshigaya Municipal Hospital, 10-47-1

Higashi-Koshigaya, Koshigaya, Saitama 343-0023, Japan

Full list of author information is available at the end of the article
} 


\section{Background}

Since low-dose aspirin was found to suppress platelet aggregation [1], several clinical trials have demonstrated its antiplatelet efficacy [2]. Low-dose aspirin is widely used for angina pectoris, myocardial infarction, ischemic cerebro-vascular disease, Kawasaki disease, and for prevention of thromboembolism after cardiac surgery. It inhibits cyclooxygenase-1 (COX-1) in the platelets, suppresses arachidonic acid metabolism, and prevents the synthesis of thromboxane $\mathrm{A}_{2}\left(\mathrm{TXA}_{2}\right)$, a compound that induces platelet aggregation [3]. Aspirin is considered to suppress platelet aggregation by acetylating platelet COX-1 in portal immediately after taking the medication [4]. Aspirin acts on the internal COX-1 and irreversibly acetylates Ser529 [3]. Access to COX-1 active site, responsible for $\mathrm{TXA}_{2}$ synthesis, is then impeded for the lifetime of the platelet. When COX-1 in the platelets is acetylated by aspirin, the antiplatelet effects of aspirin are suggested to depend on platelet turnover and to be maintained until new platelets, unacetylated by aspirin, are produced [5].

Nonsteroidal anti-inflammatory drugs (NSAIDs), including ibuprofen and loxoprofen, are widely used as analgesics, antipyretics, and anti-inflammatory agents [6]. NSAIDs also inhibit the access to COX-1 active site for $\mathrm{TXA}_{2}$ synthesis; however, the mechanism of inhibition involves formation of a salt bridge with Arg120 of COX-1, unlike aspirin [7]. Suppression of the platelet function by NSAIDs is limited to a fixed period after their administration, because COX-1 inhibition is reversible [8].

Some patients with cardiovascular disorders using lowdose aspirin simultaneously take NSAIDs for relief of pain resulting from conditions, such as rheumatoid arthritis [9]. The antiplatelet effects of aspirin may be decreased due to co-administration of ibuprofen $[3,10,11]$, and a warning is included in the package inserts of both aspirin and ibuprofen. When ibuprofen binds with COX-1, it hinders acetylation of the serine residue by aspirin [3]. Therefore, aspirin needs to bind with COX-1 before ibuprofen administration to avoid this interaction. It has been reported that the reduction of the antiplatelet effects of aspirin was avoided by taking aspirin $2 \mathrm{~h}$ before ibuprofen administration [3]. Although this dosage regimen is only useful in case of single daily dose of aspirin and ibuprofen, it is considered that the antiplatelet effects of daily lowdose aspirin (once a day) are competitively inhibited by the prolonged use of multiple daily doses of ibuprofen (three times a day), even when aspirin was taken before ibuprofen administration [3, 10, 11]. COX-1 inhibition seems to persist when aspirin is taken on the next day, in spite of the 12-h period since the last dose of ibuprofen.

Loxoprofen sodium is more frequently prescribed than ibuprofen in Japan $[9,12]$. The antiplatelet effects of aspirin were found to be suppressed by loxoprofen; however, we previously reported that this interaction might be avoided by taking aspirin $2 \mathrm{~h}$ before loxoprofen in continuous dosing [13]. In other words, this interaction might be avoided by taking aspirin $12 \mathrm{~h}$ after loxoprofen administration.

Some patients take NSAIDs irregularly in case of pain and self-adjustment. Thus, it seems to be difficult to secure $12 \mathrm{~h}$ to avoid this interaction. The minimum time interval that should separate the administration of aspirin and loxoprofen to avoid their interaction is not well known. In addition, there are two forms of aspirin tablets, uncoated and enteric-coated tablets. Entericcoated aspirin tablets result in a slower inhibitory effect on platelet COX-1 than the uncoated aspirin tablets [14]. Therefore, NSAIDs might have different effects depending on the dosage form of aspirin.

We previously reported that the antiplatelet effect of aspirin was inhibited by ibuprofen but not the other five NSAIDs investigated in an in vitro experimental study [15]. In this report, the final concentrations of the NSAIDs were their maximum plasma concentrations $\left(\mathrm{C}_{\max }\right)$ obtained after one clinical dose. We considered that the antiplatelet effect of the NSAIDs might apparently conceal their interaction with aspirin. The extent to which the antiplatelet effect of aspirin was affected was thought to be depended on the COX-1 inhibitory activity of each NSAID.

In this study, we investigated that the time interval required to avoid the influence of NSAIDs on the antiplatelet effects of aspirin. An in vitro experiment was performed, in which aspirin and NSAIDs were added to human blank blood, to investigate the influence of NSAIDs at various concentrations on the antiplatelet action of aspirin. The fluctuation of the serum drug concentration with time was considered. We washed the platelet to avoid the antiplatelet effect of the NSAIDs, which apparently could affect their interaction with aspirin.Two NSAIDs, ibuprofen and loxoprofen, were used. Some information is known about the interaction of ibuprofen with aspirin; however, only limited information is known in case of loxoprofen. Moreover, we investigated the best timing for taking aspirin, in case of both uncoated and enteric-coated tablets, and NSAIDs to avoid the reduction of the antiplatelet effects of lowdose aspirin.

\section{Methods \\ Chemicals}

Aspirin (Lot. No. TSH5399), ibuprofen (Lot. No. TSG6469 and KWF6951) were obtained from Wako Pure Chemical Industries (Osaka, Japan). Loxoprofen-trans$\mathrm{OH}$ (a mixture of four isoforms of trans-OH loxoprofen metabolites, Lot. No. L-0179-046-T) was kindly provided by Daiichi Sankyo Company (Tokyo, Japan). HEPES (Lot. 
No. EX146, EQ115, CW082, and DB223) was obtained from Dojindo Laboratories (Kumamoto, Japan). Dimethyl sulfoxide (DMSO, Lot. No. 911 W1022 and 107 N1039) was obtained from Kanto Chemical Industries (Tokyo, Japan). Human plasma albumin (Lot. No. M9G6056 and M2M2762) was obtained from Nacalai tesque (Kyoto, Japan). Collagen (Lot. No. C003, 0538, 0540, and 0543), as a platelet aggregation stimulus, was obtained from Arkray (Kyoto, Japan). All other chemicals were of analytical grade.

\section{Blood collection}

Blood samples were collected from healthy adult volunteers, including both men and women $(n=6$, however $n=5$ for groups added the concentration after $12 \mathrm{~h}$ of taking one clinical dose). Inclusion criteria were nonsmokers, not taking aspirin within 2 weeks or other medications (containing NSAIDs) within 1 week before blood collection, and avoiding alcohol, fatty meals, and large amounts of spinach, garlic, Chinese chive, and onion after the evening meal on the day before blood collection because they may affect platelet aggregation activity [16, 17]. About $20 \mathrm{~mL}$ of blood was collected using a $21 \mathrm{G}$ needle into a plastic syringe containing $2 \mathrm{~mL}$ of acid-citrate-dextrose (ACD)-A solution. The blood was divided into plastic tubes containing $5 \mathrm{~mL}$ each and centrifuged at $200 \mathrm{~g}$ for $10 \mathrm{~min}$ at $25^{\circ} \mathrm{C}$. Platelet rich plasma (PRP) was obtained from the supernatant of the blood. Study protocols were approved by the ethics committee for human material analysis study of the Tokyo University of Science (approval number 10001, 13002).

\section{Addition of drugs to platelets}

Aspirin, ibuprofen and loxoprofen-trans-OH were suspended in a little volume of DMSO, diluted with saline containing $0.1 \%$ human plasma albumin and $1 \%$ DMSO $(0.1 \% \mathrm{Alb})$ [18]. The final concentration of aspirin was $17 \mu \mathrm{M}$, which was enough to induce antiplatelet effects in the in vitro experimental protocol that adding drugs to PRP. When the final concentration of aspirin was lower than $17 \mu \mathrm{M}$, the PATI values were not steady. In contrast, when the final concentration of aspirin was much higher than $17 \mu \mathrm{M}$, platelet aggregation was hardly induced by the highest concentration of collagen $(10 \mu \mathrm{g} / \mathrm{mL})$. Therefore, it was impossible to measure the PATI values. The final concentrations of NSAIDs (ibuprofen and loxoprofen-trans-OH) were their $\mathrm{C}_{\max }$, the concentration after $6 \mathrm{~h}$ (for loxoprofen only), and the concentration after $12 \mathrm{~h}$ of taking one clinical dose (ibuprofen, $200 \mathrm{mg}$; loxoprofen, $60 \mathrm{mg}$, Table 1) $[19,20]$. The concentration of NSAIDs after $12 \mathrm{~h}$ is assumed to be equal to that before taking aspirin (at 7:00 in the next morning) in a dosage regimen involving NSAID administration 3 times a day (at 9:00, 13:00, and 19:00). A control, aspirin only, and NSAID plus aspirin groups were studied for each NSAID. In NSAID plus aspirin group, aspirin was added to PRP 6 min after NSAID addition. Each fluid volume was $1 \mathrm{~mL}$ (PRP), $111 \mu \mathrm{L}$ (NSAID solution), and $123 \mu \mathrm{L}$ (aspirin solution). In aspirin only group, $0.1 \%$ Alb was added instead of the NSAID while in the control group, 0.1\%Alb was added instead of aspirin and NSAID. Because platelet COX-1 was inhibited by aspirin or NSAIDs within $5 \mathrm{~min}$ [21] in an in vitro experimental study and platelet aggregation rate may be fluctuant if the elapsed time after aspirin addition was not constant; therefore, preparation of washed platelets started 6 min after aspirin addition.

\section{Measurement of platelet aggregation}

Plt-HEPES solution containing $1 \mathrm{mM} \mathrm{MgCl} 2,20 \mathrm{mM}$ HEPES, $0.13 \mathrm{M} \mathrm{NaCl}, 2 \mathrm{mM} \mathrm{KCl}$, and $0.4 \mathrm{mM} \mathrm{NaH}_{2} \mathrm{PO}_{4}$ was prepared. Then, the PRP-drug solution mixture with added buffer (Plt-HEPES solution: ACD-A solution $=9$ : 1) was centrifuged at $25{ }^{\circ} \mathrm{C}, 520 \mathrm{~g}$ for $10 \mathrm{~min}$, and the obtained platelet pellets were re-suspended in PltHEPES solution and $\mathrm{CaCl}_{2}$ solution was added (final concentration of $\mathrm{CaCl}_{2}$ was $2 \mathrm{mM}$ ).

Platelet aggregation was measured using a light transmission aggregometer, PRP313M (IMI Co., Ltd., Saitama, Japan), according to the Born and Cross method [22]. One-hundred microliters of platelet suspension were pre-incubated in a cuvette at $37{ }^{\circ} \mathrm{C}$ for $3 \mathrm{~min}$ in the PRP313M. Platelet aggregation was measured using collagen as a stimulus for $5 \mathrm{~min}$. The final concentrations of collagen in the platelet suspension were $0.5,2,5$, and

Table 1 Concentration of each drug in the additional experiment

\begin{tabular}{lc}
\hline Drug & Concentration $(\mu \mathrm{M})$ \\
\hline Aspirin & 17 \\
Ibuprofen (maximum plasma concentration after taking ibuprofen $200 \mathrm{mg})$ & $80.5[19]$ \\
Ibuprofen (assumed concentration after $12 \mathrm{~h}$ of taking ibuprofen $200 \mathrm{mg})$ & $2[19]^{\mathrm{a}}$ \\
Loxoprofen-trans-OH (maximum plasma concentration after taking loxoprofen $60 \mathrm{mg})$ & $3.4[20]$ \\
Loxoprofen-trans-OH (assumed concentration after $6 \mathrm{~h}$ of taking loxoprofen $60 \mathrm{mg})$ & $0.16[20]$ \\
Loxoprofen-trans-OH (assumed concentration after $12 \mathrm{~h}$ of taking loxoprofen $60 \mathrm{mg})$ & $0.0046[20]$ \\
\hline
\end{tabular}

${ }^{a}$ Concentration was simulated using a 1-compartment model 
$10 \mu \mathrm{g} / \mathrm{mL}$. Assuming the light transmission through the buffer to be $100 \%$, that of the platelet suspension represented the platelet aggregation rate. Platelet aggregation was measured within 1 to $2 \mathrm{~h}$ after blood collection because the platelet aggregability was stable during this period [23].

\section{Data analysis}

\section{1) Platelet aggregation rate}

The maximum aggregation rates induced by collagen at the four concentrations used were connected as a grading curve. The maximum aggregation rate induced by the highest concentration of collagen $(10 \mu \mathrm{g} / \mathrm{mL})$ was defined as $100 \%$ of platelet suspension, and the putative agonist-concentration giving 50\% aggregation was calculated and defined as platelet aggregation threshold index (PATI, Fig. 1) [24]. Therefore, the increase in PATI means that the platelet aggregation activity was inhibited because a higher concentration of the stimulus was needed to induce platelet aggregation. The PATI values represent the mean \pm SEM.

Besides, there are inter-individual and intra-individual differences in the platelet aggregation activity [25], thus we also measured platelet aggregation in a drug-free group $(0.1 \% \mathrm{Alb})$ as a control in each additional condition.

\section{2) Measurement of thromboxane $B_{2}\left(T X B_{2}\right)$ level in platelet suspension}

Platelet COX-1 activity was determined by measuring serum levels of $\mathrm{TXB}_{2}$, the major stable metabolite of $\mathrm{TXA}_{2}$. $\mathrm{TXB}_{2}$ level in platelet suspension was determined using enzyme-linked immunosorbent assay (Thromboxane $\mathrm{B}_{2}$ EIA Kit, Cayman Co., Ann Arbor, Michigan, USA). To measure $\mathrm{TXB}_{2}$ derived from platelet COX-1, $\mathrm{TXB}_{2}$ concentration in the supernatant of the collagenstimulated platelet suspension was determined [26]. Platelet suspension was stimulated with 2 or $5 \mu \mathrm{g} / \mathrm{mL}$ collagen for $5 \mathrm{~min}$, followed by centrifugation at $4{ }^{\circ} \mathrm{C}$,
$2000 \mathrm{~g}$ for $15 \mathrm{~min}$ to remove platelets. Supernatants were stored at $-30{ }^{\circ} \mathrm{C}$ until analysis.

\section{3) Statistical analysis}

Tukey's test was used to compare PATI and $\mathrm{TXB}_{2}$ concentrations in platelet suspension in each condition. $P$ value $<0.05$ is considered statistically significant.

\section{Results}

\section{Added NSAIDs: ibuprofen}

The PATI values of the control and ibuprofen $\left(C_{\max }\right)$ plus aspirin groups were $3.0 \pm 0.3$ and $3.7 \pm 0.3 \mu \mathrm{g} / \mathrm{mL}$, respectively. These values were lower than that of the aspirin only group $(5.5 \pm 0.3 \mu \mathrm{g} / \mathrm{mL}$, Fig. $2 \mathrm{a}) . \mathrm{TXB}_{2}$ concentrations in platelet suspension of the control, aspirin only, and ibuprofen $\left(\mathrm{C}_{\max }\right)$ plus aspirin groups were $1400 \pm 300,200 \pm 30$, and $930 \pm 290 \mathrm{ng} / \mathrm{mL}$, respectively, which decreased with increasing PATI (Fig. 3a). When ibuprofen was used at the assumed concentration after $12 \mathrm{~h}$ of taking one clinical dose, PATI of the control, aspirin only and ibuprofen plus aspirin groups were $1.6 \pm$ $0.5,5.1 \pm 0.6$, and $2.6 \pm 0.5 \mu \mathrm{g} / \mathrm{mL}$, respectively (Fig. 2b). $\mathrm{TXB}_{2}$ concentrations in platelet suspension of the control, aspirin only and ibuprofen plus aspirin groups were $580 \pm 150,85 \pm 19$, and $650 \pm 170 \mathrm{ng} / \mathrm{mL}$, respectively, which decreased with increasing PATI (Fig. 3b). PATI in the ibuprofen plus aspirin group was lower than that in the aspirin only group, regardless of the concentration of ibuprofen. Additionally, the PATI values and $\mathrm{TXB}_{2}$ concentrations of the platelet suspension of the group treated with ibuprofen only were nearly equal to those of each control group, regardless of their concentrations (data not shown).

\section{Added NSAIDs: loxoprofen-trans-OH}

The PATI values of the aspirin only and loxoprofentrans $-\mathrm{OH}\left(\mathrm{C}_{\max }\right)$ plus aspirin groups were $5.9 \pm 0.1$ and $4.1 \pm 0.1 \mu \mathrm{g} / \mathrm{mL}$, respectively. These values were higher
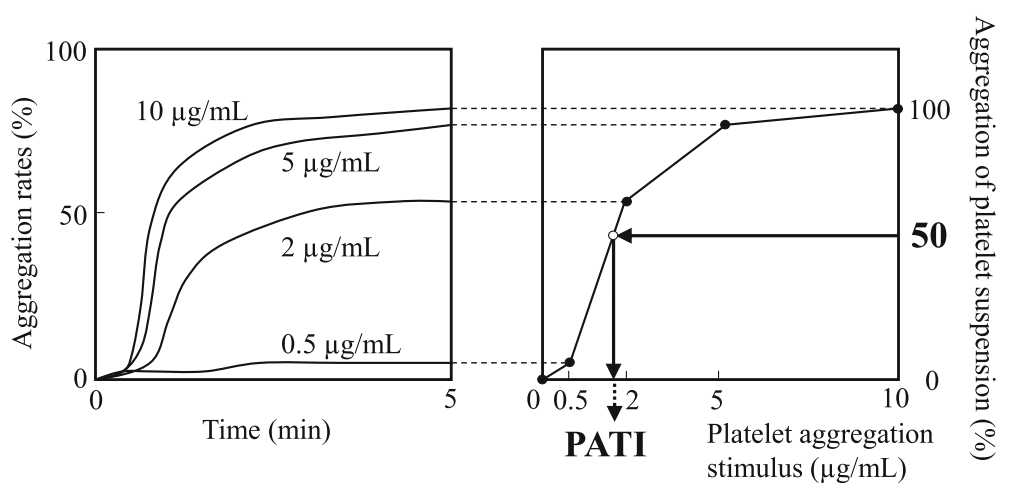

Fig. 1 Calculation method of platelet aggregation threshold index (PATI [24]). Light transmission curves were obtained from four experiments (collagen concentration, A: 0.5, B: 2, C: 5, and D: $10 \mu \mathrm{g} / \mathrm{mL}$ ) 


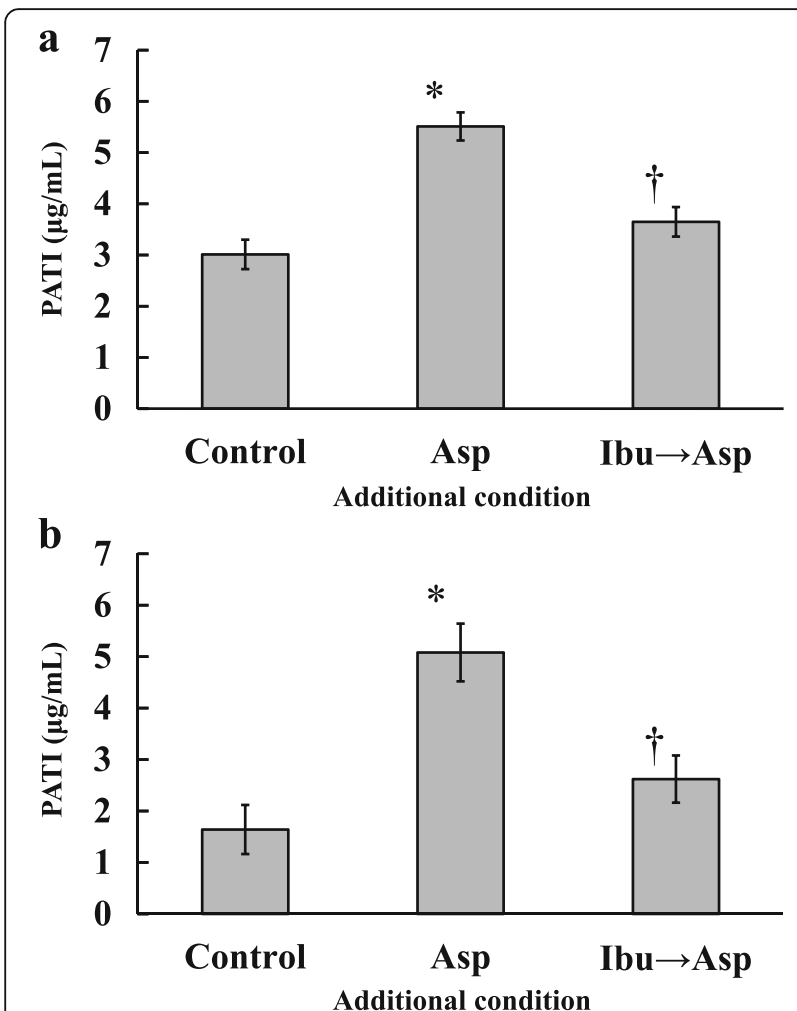

Fig. 2 Effect of aspirin (Asp) and aspirin after ibuprofen (lbu $\rightarrow$ Asp) addition on platelet aggregation threshold index (PATI). Ibuprofen concentration of (a): maximum concentration after taking ibuprofen at a dose of $200 \mathrm{mg}$, (b): the concentration $12 \mathrm{~h}$ after taking ibuprofen at a dose of $200 \mathrm{mg}$. ( $n=6$ for $\mathrm{a}, n=5$ for $\mathrm{b}$; ${ }^{*} P<0.05$ compared with the control; $+P<0.05$ compared with the aspirin only group; These values represent the mean \pm SEM.)

than that of the control $(3.3 \pm 0.1 \mu \mathrm{g} / \mathrm{mL}$, Fig. 4a). PATI of the loxoprofen-trans- $\mathrm{OH}\left(\mathrm{C}_{\max }\right)$ plus aspirin group was significantly decreased compared to that of the aspirin only group. $\mathrm{TXB}_{2}$ concentrations in platelet suspension of the control, aspirin only, and loxoprofentrans- $\mathrm{OH}\left(\mathrm{C}_{\max }\right)$ plus aspirin groups were $1200 \pm 700$, $190 \pm 120,1100 \pm 700 \mathrm{ng} / \mathrm{mL}$, respectively (Fig. 5a). Each data showed that $\mathrm{TXB}_{2}$ concentrations decreased with increasing PATI; however, two of the six subjects showed scores that were several times higher than the $\mathrm{TXB}_{2}$ concentrations of the others. When loxoprofen was used at the assumed concentration after $6 \mathrm{~h}$ of taking a clinical dose of loxoprofen sodium, PATI of the aspirin only and loxoprofen-trans-OH plus aspirin groups were $5.0 \pm$ 0.5 and $4.9 \pm 0.4 \mu \mathrm{g} / \mathrm{mL}$, respectively. These values were higher than that of the control $(2.7 \pm 0.3 \mu \mathrm{g} / \mathrm{mL}$, Fig. $4 \mathrm{~b})$. In addition, $\mathrm{TXB}_{2}$ concentrations in the aspirin only and loxoprofen-trans-OH plus aspirin groups were $26 \pm 10$ and $33 \pm 12 \mathrm{ng} / \mathrm{mL}$, respectively, which was lower than that of the control $(260 \pm 120 \mathrm{ng} / \mathrm{mL}$, Fig. 5b). PATI and $\mathrm{TXB}_{2}$ concentrations in platelet suspension showed no significant differences between the aspirin only and

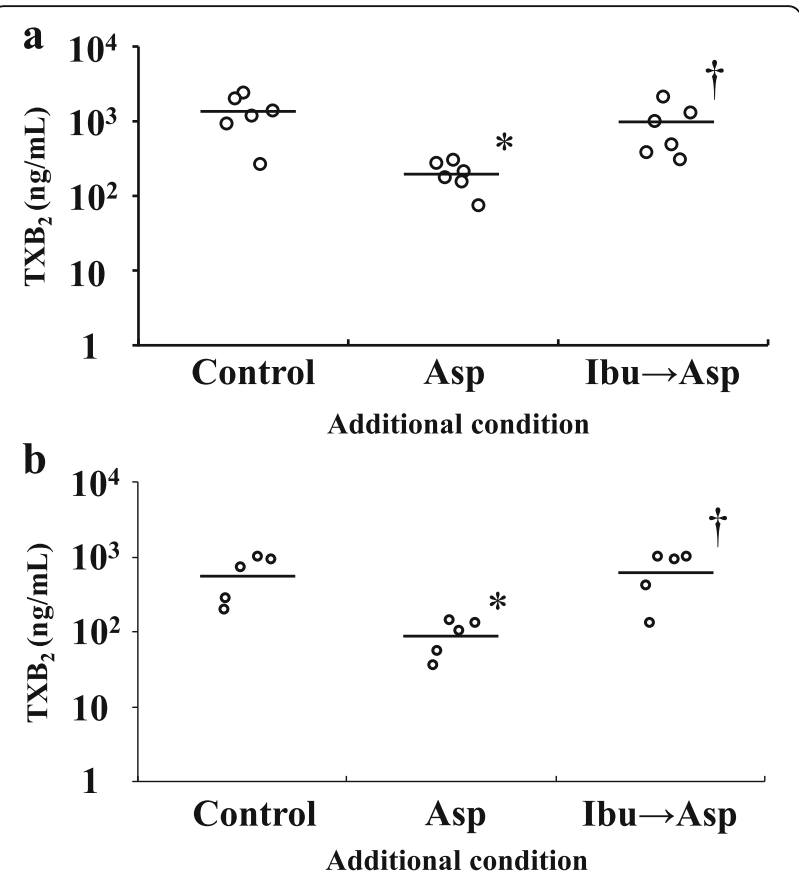

Fig. $3 \mathrm{TXB}_{2}$ concentration of aspirin (Asp) and aspirin after ibuprofen (Ibu $\rightarrow$ Asp) addition. Ibuprofen concentration of (a): maximum concentration after taking ibuprofen at a dose of $200 \mathrm{mg}$, (b): the concentration $12 \mathrm{~h}$ after taking ibuprofen at a dose of $200 \mathrm{mg}$. ( $n=6$ for $a, n=5$ for $b$; ${ }^{*} P<0.05$ compared with the control; $+P<0.05$ compared with the aspirin only group; The line indicates the mean value.)

loxoprofen-trans-OH plus aspirin groups. Similar results were obtained when loxoprofen was used at the assumed concentration after $12 \mathrm{~h}$ of taking a clinical dose of loxoprofen sodium (Figs. 4c and 5c). Additionally, the PATI values and $\mathrm{TXB}_{2}$ concentrations of the platelet suspension of loxoprofen-trans-OH only groups were nearly equal to those of each control group, regardless of their concentrations (data not shown).

\section{Discussion}

The antiplatelet effects of aspirin were suppressed when aspirin was added after ibuprofen, regardless of the concentration of ibuprofen. $\mathrm{TXB}_{2}$ level in platelet suspension in the ibuprofen plus aspirin group was higher than that in the aspirin only group. Platelet COX-1 inhibition by aspirin was considered to be decreased (Fig. 3a and b). Besides, PK/PD analysis showed that taking aspirin $2 \mathrm{~h}$ before ibuprofen can avoid this interaction, whereas taking ibuprofen $12 \mathrm{~h}$ before aspirin cannot avoid this interaction [27]. The binding constant of ibuprofen to COX-1 $\left(2.48 \mu \mathrm{M}^{-1} \cdot \mathrm{hr}^{-1}\right)$ is larger than that of aspirin $\left(0.027 \mu \mathrm{M}^{-1} \cdot \mathrm{hr}^{-1}\right)$ [28], and the concentration of ibuprofen $12 \mathrm{~h}$ after taking the medication (about $2 \mu \mathrm{M}$ ) is nearly equal to the half maximal inhibitory concentration $\left(\mathrm{IC}_{50}\right)$ of ibuprofen to COX-1 $(3.0-4.8 \mu \mathrm{M})$ [29-31]. This 


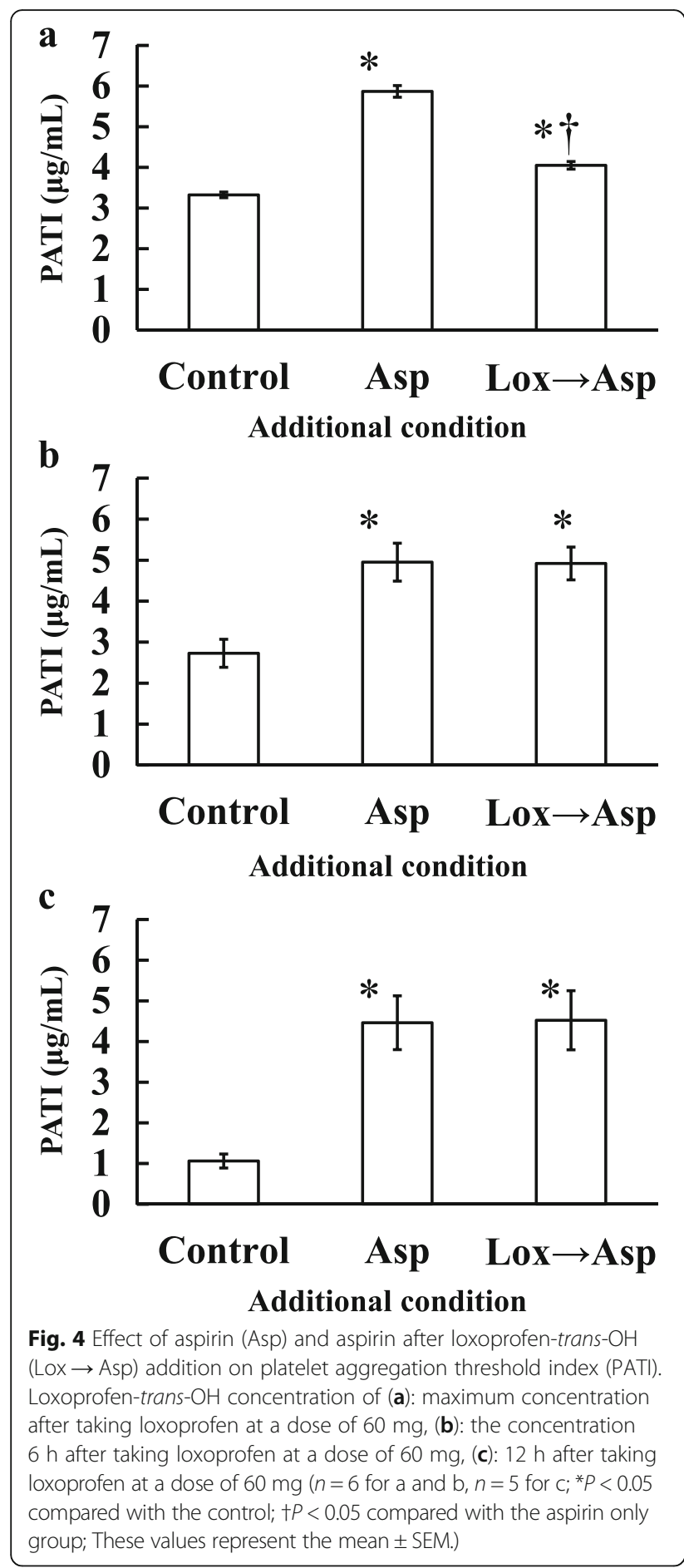

concentration seems to be enough to inhibit the antiplatelet effects of aspirin. Regarding the usual once-daily lowdose aspirin regimen, it is difficult to avoid the interaction between aspirin and ibuprofen because the antiplatelet effects of aspirin are suppressed by ibuprofen even if aspirin is taken $12 \mathrm{~h}$ after ibuprofen administration. It is possible to avoid this interaction when the dosing interval from ibuprofen to aspirin is $22 \mathrm{~h}$ (in other words, from aspirin

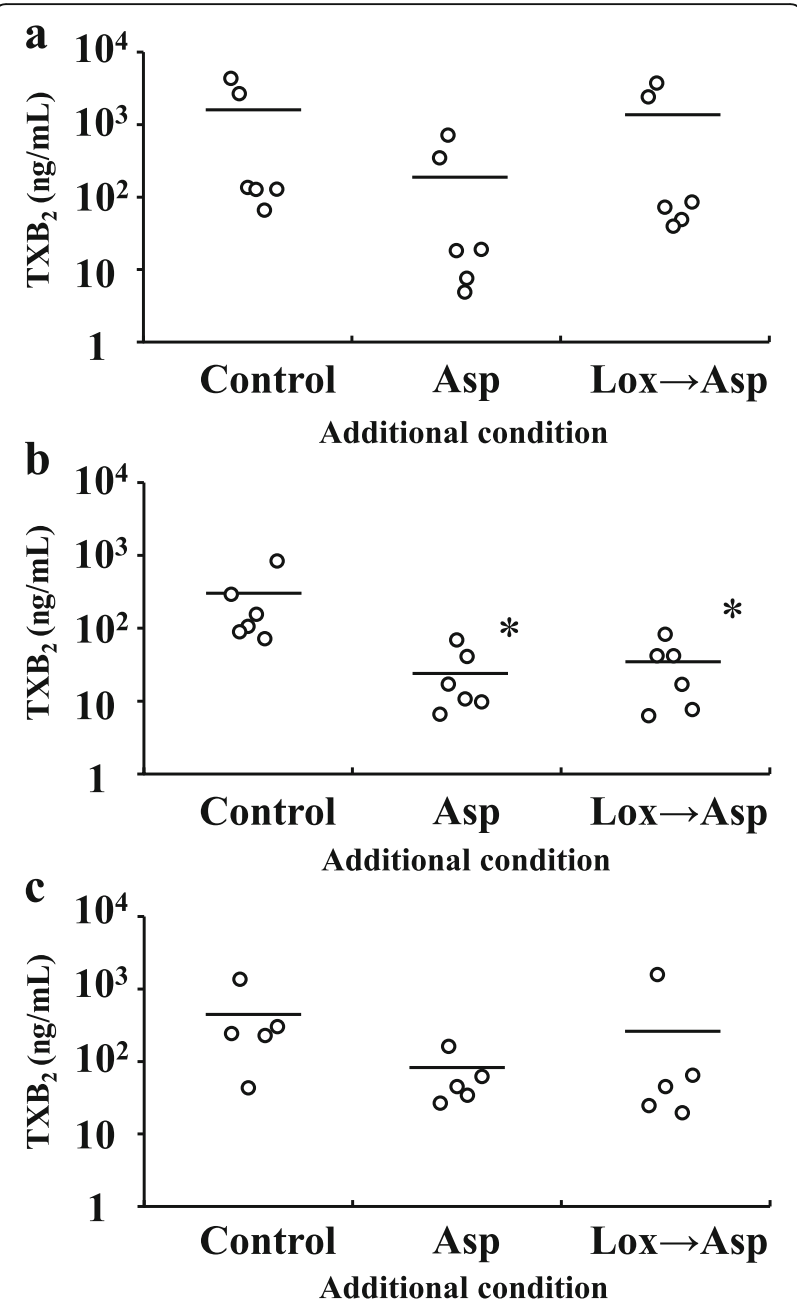

Fig. $5 \mathrm{TXB}_{2}$ concentration of aspirin (Asp) and aspirin after loxoprofen-trans-OH (Lox $\rightarrow$ Asp) addition. Loxoprofen-trans-OH concentration of (a): maximum concentration after taking loxoprofen at a dose of $60 \mathrm{mg}$, (b): the concentration $6 \mathrm{~h}$ after taking loxoprofen at a dose of $60 \mathrm{mg}$, (c): the concentration $12 \mathrm{~h}$ after taking loxoprofen at a dose of $60 \mathrm{mg}\left(n=6\right.$ for $\mathrm{a}$ and $\mathrm{b}, n=5$ for $\mathrm{c}$; ${ }^{*}<0.05$ compared with the control; The line indicates the mean value.)

to ibuprofen is $2 \mathrm{~h}$ ) in this once-daily regimen [3]; however, it is a considerably limited condition. Thus, it is desirable to avoid taking ibuprofen by patients on low-dose aspirin therapy.

Many studies focused on the interaction between aspirin and ibuprofen because ibuprofen is generally prescribed worldwide [6, 32]. However, since loxoprofen sodium is frequently prescribed in Japan $[9,12]$, and its price is low, loxoprofen sodium is likely to be involved in the case of taking low-dose aspirin and NSAIDs concomitantly in Japan.

Loxoprofen sodium is metabolized into four isomers of loxoprofen-trans-OH (loxoprofen-RSS, SRS, RSR, and SRR) in the human body [33]. Only loxoprofen-SRS has antipyretic, analgesic, and anti-inflammatory action, and 
inhibit platelet COX-1 [34]. Though the percentage of the SRS-isomer in loxoprofen-trans-OH used in our study was unclear, it was considered one quarter. The antiplatelet effects of aspirin were suppressed in when loxoprofen-trans-OH was added at $\mathrm{C}_{\max }$, whereas it was not suppressed when loxoprofen-trans-OH was added at the assumed concentration after $6 \mathrm{~h}$ (Fig. 4a and b). $\mathrm{TXB}_{2}$ level in platelet suspension of the loxoprofentrans- $\mathrm{OH}\left(\mathrm{C}_{\max }\right)$ plus aspirin group tended to be higher than that of the aspirin only group. All the subjects exhibited the same tendency although no significant difference was shown (Fig. 5a). However, $\mathrm{TXB}_{2}$ was not high at the assumed loxoprofen-trans- $\mathrm{OH}$ concentration after $6 \mathrm{~h}$ of taking loxoprofen dose (Fig. 5b). Therefore, the antiplatelet effects of aspirin were affected by loxoprofen; however, taking aspirin $6 \mathrm{~h}$ after loxoprofen administration could avoid this interaction. The theoretical concentrations of loxoprofen-SRS are about $0.85 \mu \mathrm{M}$ $\left(\mathrm{C}_{\max }\right)$ and $0.04 \mu \mathrm{M}$ (after $6 \mathrm{~h}$ of taking loxoprofen). The $\mathrm{C}_{\max }$ of loxoprofen-SRS after a single oral dose of loxoprofen tablet $(60 \mathrm{mg})$ was about $1.17 \mu \mathrm{M}$ [33]. The $\mathrm{IC}_{50}$ of loxoprofen-SRS to platelet COX-1 was about $0.38 \mu \mathrm{M}$ [29]. Therefore, the $\mathrm{C}_{\max }$ of loxoprofen-trans- $\mathrm{OH}$ was enough to inhibit platelet COX-1 although this inhibition was reversible, whereas loxoprofen-trans-OH concentration after $6 \mathrm{~h}$ of taking loxoprofen might be too low to inhibit COX-1. Therefore, when loxoprofentrans-OH was added at the $\mathrm{C}_{\max }$, it competitively impeded COX-1 acetylation by aspirin when NSAIDs reach the active site on platelet COX-1 earlier than aspirin [3]. Considering the theoretical concentrations of loxoprofen-SRS, platelet COX-1 was difficult to be inhibited by loxoprofen-SRS $6 \mathrm{~h}$ or more after taking loxoprofen, thus this interaction can be avoided. Loxoprofen is eliminated rapidly [20], so the effect of loxoprofen on the antiplatelet effect of aspirin was thought to decrease within $6 \mathrm{~h}$ of taking loxoprofen. The theoretical concentration of loxoprofen-SRS $4 \mathrm{~h}$ after dosing (approximately $0.14 \mu \mathrm{M}$ ) was lower than its $\mathrm{IC}_{50}$ against platelet $\mathrm{COX}-1$ (approximately $0.38 \mu \mathrm{M})[20,29]$. However, we considered that the platelet COX-1 might have been partially inhibited because the ratio of its $\mathrm{IC}_{50}$ to the concentration was only 2.7 , which might be the border line at which the interaction was observed or not. Therefore, a dosing interval of $6 \mathrm{~h}$ from when loxoprofen is administered to when aspirin is administered was considered sufficient, but it is unclear whether the dosing interval of $6 \mathrm{~h}$ is necessary or not. Further studies are needed to clarify whether a dosing interval from when loxoprofen is administered to when aspirin is administered is possible to be reduced less than $6 \mathrm{~h}$ with avoiding this interaction.

In this study, the concentration of each NSAID was determined based on the clinical single dose. Ibuprofen and loxoprofen can be taken three times a day. However, ibuprofen and loxoprofen are eliminated rapidly; therefore, they do not accumulate in the body even when they are taken continuously [35].

We studied NSAID interference with the antiplatelet effects of aspirin via COX-1 inhibitory activity of NSAIDs; however, it is necessary to consider the rate of COX-1 irreversible inhibition by aspirin, because two forms of aspirin tablets, uncoated and enteric-coated, with different solubility are widely used in Japan. Aspirin is metabolized to salicylic acid and its half-life in human plasma is approximately $5-15 \mathrm{~min}$ [36]. Platelet COX-1 is rapidly acetylated by aspirin in the portal vein during this metabolism period. This time zone was determined based on the decline in serum $\mathrm{TXB}_{2}$ concentration. A sudden decline in serum $\mathrm{TXB}_{2}$ concentration occurs 0 to $1 \mathrm{~h}$ after taking uncoated aspirin tablets [14, 37], and it is of great importance that NSAIDs bind to COX-1 and impede its acetylation by aspirin within this one hour. In other words, unless loxoprofen-SRS binding time zone to COX-1 overlaps with the COX-1 acetylation time zone by aspirin, this interaction might be avoided. Considering platelet COX-1 inhibition by loxoprofen-SRS, if loxoprofen is not administered within $6 \mathrm{~h}$ before or $1 \mathrm{~h}$ after (total $7 \mathrm{~h}$ ) taking aspirin, loxoprofen will not suppress the antiplatelet effects of uncoated aspirin tablets (Fig. 6). On the other hand, a slow decrease in serum $\mathrm{TXB}_{2}$ concentration occurs 2 to $7 \mathrm{~h}$ after taking enteric-coated aspirin tablets [14]. Thus, if loxoprofen is not administered within $4 \mathrm{~h}$ before or $7 \mathrm{~h}$ after (total $11 \mathrm{~h}$ ) taking aspirin, loxoprofen will not interfere with the antiplatelet effects (Fig. 6). Considering a lifestyle of getting up at 6:00, going to bed at 22:00 and taking aspirin at 7:00 or 19:00, the longest time period in which the interaction can be avoided is achieved by administration of aspirin uncoated tablets at 7:00, which results in a period of $14 \mathrm{~h}$ (from 8:00 to 22:00) during which the interaction can be avoidable. Thus, uncoated aspirin tablets are useful to prevent this interaction when NSAIDs are taken several times daily. As a supplement, some studies reported that gastric toxicity from aspirin could be eliminated by the use of enteric-coated tablets; however most of them were short-time studies $[38,39]$. Others reported that entericcoating might have little clinical benefits reducing gastrointestinal bleeding or ulceration longitudinally [40, 41]. Therefore, enteric-coated aspirin is considered to be not always useful to avoid gastric toxicity.

In contrast to ibuprofen and loxoprofen, celecoxib is known as a selective COX-2 inhibitor. No reduction of the antiplatelet effects of aspirin was observed with celecoxib [10]. There are several clinical trials that report the interaction between low-dose aspirin and celecoxib when uncoated aspirin tablets are used in some cases; 


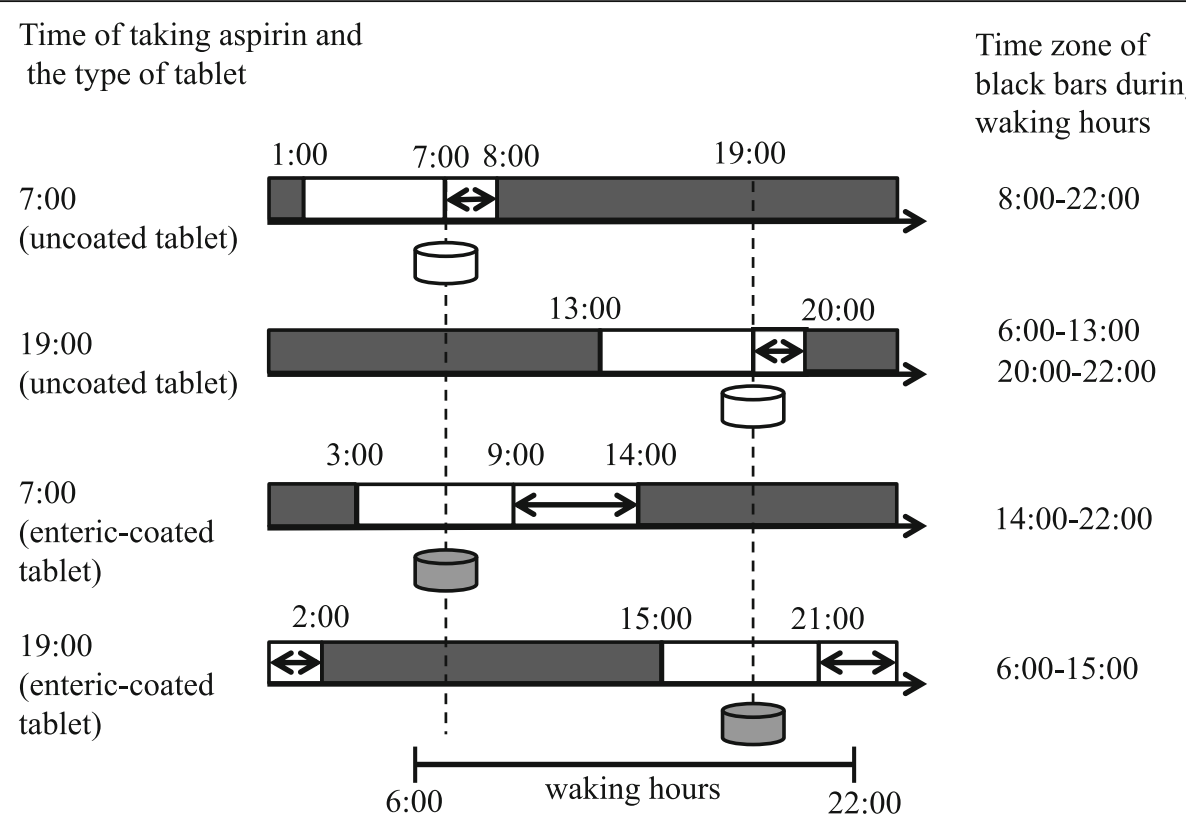

Fig. 6 Avoidable time zone in the four model cases (the time of taking aspirin and the coating of aspirin tablet are different) of taking aspirin with loxoprofen (shown as black bars). The double-headed arrows indicate the falling time zone of $\mathrm{TX}_{2}$. In these model cases, the waking time is 6:00 to $22: 00$

however, there are no reports that is specified the use of enteric-coated aspirin. Celecoxib $\mathrm{IC}_{50}$ to platelet $\mathrm{COX}-1$ was $6.7-8.3 \mu \mathrm{M}[30,31]$, and the maximum plasma concentration of celecoxib after a single oral dose of $200 \mathrm{mg}$ is about $2.1 \mu \mathrm{M}$. Celecoxib is not considered to interfere with the inhibition of platelet COX-1 by aspirin. Celecoxib was not investigated in our study; however, COX-1 inhibition by celecoxib is considered limited. It is suggested that celecoxib does not suppress the antiplatelet effects of aspirin, regardless of the kind of tablet coating.

These findings suggest that NSAIDs can influence the antiplatelet effects of aspirin depending on the time of taking both drugs and the coating of aspirin tablets. Suppression of the antiplatelet effects may lead to inefficient prevention of cardiovascular events. In fact, patients receiving aspirin plus ibuprofen showed an increased risk of cardiovascular mortality compared with those who received aspirin alone [42]. Both ibuprofen and loxoprofen are used as both ethical and over the counter drugs in Japan, thus pharmacists need to counsel the patients about the time of taking NSAIDs, including nonprescription drugs, with low-dose aspirin.

When low-dose aspirin and NSAIDs are coadministered, several reports showed that ibuprofen suppressed the antiplatelet effects of aspirin; however, celecoxib did not $[3,10,11]$. In addition, loxoprofen suppressed the antiplatelet effects when co-administered with aspirin at the same time; however, this interaction is avoidable [13]. Moreover, the extent to which this interaction is avoidable depends on the time of taking aspirin and loxoprofen, and the coating of aspirin tablets. In this model, the longest period (from 8:00 to 22:00) during which the interference with the antiplatelet effects of aspirin is avoidable, is achieved when uncoated aspirin tablets are administered at 7:00 in the morning.

\section{Conclusions}

It is desirable to avoid ibuprofen co-administration with the usual once-daily low-dose aspirin therapy; however, a 6-h interval between loxoprofen and aspirin could avoid this potential interaction when loxoprofen is taken before aspirin.

\section{Abbreviations}

ACD: Acid-citrate-dextrose; COX-1: Cyclooxygenase-1; IC 50 : The half maximal inhibitory concentration; NSAIDs: Nonsteroidal anti-inflammatory drugs; PATI: Platelet aggregation threshold index; PRP: Platelet rich plasma; TXA $_{2}$ : Thromboxane $A_{2} ; T_{X B_{2}}$ : Thromboxane $B_{2}$

\section{Acknowledgements}

The authors gratefully appreciate Daiichi-Sankyo Company for kindly providing loxoprofen- trans-OH.

\section{Funding}

This study was supported by research funds of Tokyo University of Science.

\section{Availability of data and materials}

All data generated or analyzed during this study are included in this published article.

\section{Authors' contributions}

KS, YA, and TA conceived the study. KS and NN carried out the in vitro experiment. KS and YA performed the statistical analysis. KS and YA wrote the manuscript. KS, YA, NN, HS, and TA provided editorial review and contributed to discussions. All authors read and approved the final manuscript. 


\section{Competing interests}

The authors declare that they have no competing interests.

\section{Consent for publication}

Not applicable.

\section{Ethics approval and consent to participate}

Study protocols were approved by the ethics committee for human material analysis study of the Tokyo University of Science (approval number 10001, 13002)

\section{Publisher's Note}

Springer Nature remains neutral with regard to jurisdictional claims in published maps and institutional affiliations.

\section{Author details \\ 'Faculty of Pharmaceutical Sciences, Tokyo University of Science, 264 Yamazaki, Noda, Chiba 278-8510, Japan. ${ }^{2}$ Department of Pharmacy, Koshigaya Municipal Hospital, 10-47-1 Higashi-Koshigaya, Koshigaya, Saitama 343-0023, Japan. ${ }^{3}$ Department of Pharmacy, National Hospital Organization, Yokohama Medical Center, 3-60-2 Harajuku, Totsuka, Yokohama, Kanagawa 245-8575, Japan. ${ }^{4}$ Department of Pharmacy, Chemotherapy Research Institute, Kaken Hospital, 6-1-14 Konodai, Ichikawa, Chiba 272-0827, Japan.}

Received: 18 October 2016 Accepted: 1 March 2017

Published online: 09 March 2017

\section{References}

1. Weiss HJ, Aledort LM. Impaired platelet-connective-tissue reaction in man after aspirin ingestion. Lancet. 1967;2:495-7.

2. Antithrombotic Trialists' (ATT) Collaboration. Aspirin in the primary and secondary prevention of vascular disease: collaborative meta-analysis of individual participant data from randomised trials. Lancet. 2009:373:1849-60.

3. Catella-Lawson F, Reilly MP, Kapoor SC, Cucchiara AJ, DeMarco S, Tournier B, et al. Cyclooxygenase inhibitors and the antiplatelet effects of aspirin. $\mathrm{N}$ Engl J Med. 2001;345:1809-17.

4. Pedersen AK, FitzGerald GA. Dose-related kinetics of aspirin. Presystemic acetylation of platelet cyclooxygenase. N Engl J Med. 1984;311:1206-11.

5. Burch JW, Stanford N, Majerus PW. Inhibition of platelet prostaglandin synthetase by oral aspirin. J Clin Invest. 1978;61:314-9.

6. Conaghan PG. A turbulent decade for NSAIDs: update on current concepts of classification, epidemiology, comparative efficacy, and toxicity. Rheumatol Int. 2012:32:1491-502

7. Greig GM, Francis DA, Falgueyret JP, Ouellet M, Percival MD, Roy P, et al. The interaction of arginine 106 of human prostaglandin G/H synthase-2 with inhibitors is not a universal component of inhibition mediated by nonsteroidal anti-inflammatory drugs. Mol Pharmacol. 1997:52:829-38.

8. Cronberg S, Wallmark E, Söderberg I. Effect on platelet aggregation of oral administration of 10 non-steroidal analgesics to humans. Scand J Haematol. 1984:33:155-9.

9. Ito N, Yokoyama H, Soeda S, Suzuki Y, Ikeda N, Tokuoka K, et al. Investigation into the Combination of Aspirin with Non-steroidal Antiinflammatory Drugs. Yakugaku Zasshi. 2011;131:1073-7.

10. Renda G, Tacconelli S, Capone ML, Sacchetta D, Santarelli F, Sciulli MG, et al. Celecoxib, ibuprofen, and the antiplatelet effect of aspirin in patients with osteoarthritis and ischemic heart disease. Clin Pharmacol Ther. 2006;80:264-74.

11. Schuijt MP, Huntjens-Fleuren HW, de Metz M, Vollaard EJ. The interaction of ibuprofen and diclofenac with aspirin in healthy volunteers. Br J Pharmacol. 2009;157:931-4.

12. Ise $Y$, Murota $Y$, Takayama K, Narita M, Suzuki T, Soh $S$, et al. The analysis of prescription frequency and the factors on adverse reactions of NSAIDs for post-operative pain in orthopedic patients. Yakugaku Zasshi. 2003;123:613-8.

13. Akagi Y, Shibata K, Shimada S, Yanaka A, Higami Y, Tsuchiya T, et al. Influence of Loxoprofen Sodium on Antiplatelet Effect of Aspirin and How to Avoid this Interaction. Jpn J Pharm Health Care Sci. 2011:37: 69-77.
14. Jakubowski JA, Stampfer MJ, Vaillancourt R, Deykin D. Cumulative antiplatelet effect of low-dose enteric coated aspirin. Br J Haematol. 1985; 60:635-42.

15. Akagi Y, Shibata K, Nio Y, Yanaka A, Higami Y, Shimada S, et al. Influence of NSAIDs on Antiplatelet Effects of Aspirin-In vitro Experimental Study Involving NSAID Addition to Human Blood-. Jpn J Pharm Health Care Sci. 2010;36:382-91.

16. Onai R. Proper use of the supplement and guidance. J Pract Pharm. 2004;55: $1831-8$.

17. Namiki K, Yamanaka M, Tateyama C, Igarashi M, Namiki M. Platelet aggregation inhibitory activity of tea extracts. Japanese Soc Food Sci Technol. 1991;38:189-95.

18. Harada K, Katayama S, Shirota H, Chiba K, Horizoe T, Abe Y. Inhibitory effects of satigrel (E5510) on in vitro aggregation of platelets from several animal species. Jpn Pharmacol Ther. 1996:24 Suppl 2:S289-98.

19. Drug Interview form of BRUFEN 3rd edition, Kaken Pharmaceutical.

20. Naganuma H, Mochizuki Y, Kawahara Y. Study of Pharmacokinetics following Oral Administration of Loxoprofen Sodium (CS-600) in Humans. Rinsyo lyaku. 1986:2:1219-37.

21. Callan $\mathrm{OH}$, So OY, Swinney DC. The kinetic factors that determine the affinity and selectivity for slow binding inhibition of human prostaglandin $\mathrm{H}$ synthase 1 and 2 by indomethacin and flurbiprofen. J Biol Chem. 1996;271: 3548-54.

22. BORN GV. Aggregation of blood platelets by adenosine diphosphate and its reversal. Nature. 1962;194:927-9.

23. Asada R. Influence of Measurement Conditions on Platelet Aggregation Using Light Scattering. Igaku Kensa. 2008;57:1223-30.

24. Tabuchi A, Taniguchi R, Takahashi K, Kondo H, Kawato M, Morimoto T, et al. Action of aspirin on whole blood-aggregation evaluated by the screen filtration pressure method. Circ J. 2008;72:420-6.

25. Uehara $\mathrm{S}$, Izawa $\mathrm{H}$, Agetsuma $\mathrm{H}$, Adachi M, Inagaki $\mathrm{H}$. The study of blood clotting and platelet aggregation in chronic-phase cerebral infarction patients; the influence of circadian rhythm, low-dose aspirin and exercise. Japanese J Appl Physiol. 1992;22:467-75.

26. Ohmori T, Yatomi Y, Nonaka T, Kobayashi Y, Madoiwa S, Mimuro J, et al. Aspirin resistance detected with aggregometry cannot be explained by cyclooxygenase activity: involvement of other signaling pathway(s) in cardiovascular events of aspirin-treated patients. J Thromb Haemost. 2006:4:1271-8.

27. Awa K, Satoh H, Hori S, Sawada Y. Prediction of time-dependent interaction of aspirin with ibuprofen using a pharmacokinetic/pharmacodynamic model. J Clin Pharm Ther. 2012;37:469-74.

28. Hong Y, Gengo FM, Rainka MM, Bates VE, Mager DE. Populationpharmacodynamic modelling of aspirin- and ibuprofen-induced inhibition of platelet aggregation in healthy subjects. Clin Pharmacokinet. 2008:47:129-37.

29. Kawai S, Nishida S, Kato M, Furumaya Y, Okamoto R, Koshino T, et al. Comparison of cyclooxygenase- 1 and -2 inhibitory activities of various nonsteroidal anti-inflammatory drugs using human platelets and synovial cells. Eur J Pharmacol. 1998:347:87-94.

30. Riendeau D, Percival MD, Brideau C, Charleson S, Dubé D, Ethier D, et al. Etoricoxib (MK-0663): preclinical profile and comparison with other agents that selectively inhibit cyclooxygenase-2. J Pharmacol Exp Ther. 2001;296: $558-66$

31. Gierse JK, Zhang Y, Hood WF, Walker MC, Trigg JS, Maziasz TJ, et al. Valdecoxib: assessment of cyclooxygenase-2 potency and selectivity. $J$ Pharmacol Exp Ther. 2005;312:1206-12.

32. Paíga P, Santos LH, Amorim CG, Araújo AN, Montenegro MC, Pena A, et al. Pilot monitoring study of ibuprofen in surface waters of north of Portugal. Environ Sci Pollut Res Int. 2013;20:2410-20.

33. Takasaki W, Tanaka Y. Application of antibody-mediated extraction for the stereoselective determination of the active metabolite of loxoprofen in human and rat plasma. Chirality. 1992:4:308-15.

34. Noguchi M, Kimoto A, Gierse JK, Walker MC, Zweifel BS, Nozaki K, et al. Enzymologic and pharmacologic profile of loxoprofen sodium and its metabolites. Biol Pharm Bull. 2005;28:2075-9.

35. Akagi $Y$, Arai M, Shimomura H, Yamamoto K, Aoyama T. Pharmacokinetics/ pharmaco- dynamics analysis of antiplatelet effects of non-steroidal antiinflammatory drugs. Jpn J Pharm Health Care Sci. 2015:41:404-14.

36. Rowland M, Riegelman S, Harris PA, Sholkoff SD. Absorption kinetics of aspirin in man following oral administration of an aqueous solution. J Pharm Sci. 1972;61:379-85. 
37. Hoshi K, Zhou X, Terazono M, Satou Y, Yamazaki J, Miyake F. Intermittent administration of aspirin, once or twice a week. Jpn J Clin Pharmacol Ther. 2001;32:223-30.

38. Hawthorne AB, Mahida YR, Cole AT, Hawkey CJ. Aspirin-induced gastric mucosal damage: prevention by enteric-coating and relation to prostaglandin synthesis. Br J Clin Pharmacol. 1991;32:77-83.

39. Lanza FL, Royer Jr GL, Nelson RS. Endoscopic evaluation of the effects of aspirin, buffered aspirin, and enteric-coated aspirin on gastric and duodenal mucosa. N Engl J Med. 1980;303:136-8.

40. Derry S, Loke YK. Risk of gastrointestinal haemorrhage with long term use of aspirin: meta-analysis. BMJ. 2000;321:1183-7.

41. Kelly JP, Kaufman DW, Jurgelon JM, Sheehan J, Koff RS, Shapiro S. Risk of aspirin- associated major upper-gastrointestinal bleeding with entericcoated or buffered product. Lancet. 1996;348:1413-6.

42. MacDonald TM, Wei L. Effect of ibuprofen on cardioprotective effect of aspirin. Lancet. 2003;361:573-4.

Submit your next manuscript to BioMed Central and we will help you at every step:

- We accept pre-submission inquiries

- Our selector tool helps you to find the most relevant journal

- We provide round the clock customer support

- Convenient online submission

- Thorough peer review

- Inclusion in PubMed and all major indexing services

- Maximum visibility for your research

Submit your manuscript at www.biomedcentral.com/submit
Biomed Central 